\title{
Sistema de Información Territorial (S.I.T.) de la Dirección Provincial de Catastro y Cartografía de la Provincia del Chaco
}

\begin{abstract}
Arq. Hilda Mariana MEDINA. Ing. Ilse Gisela HODAPP. Sra. Clementina Isabel SANCHEZ. Sra. Silvia Elizabeth GOMEZ. Sra. Silvia Fernanda COMBAZ. i.hodapp@ecomchaco.com.ar. Dirección Provincial de Catastro y Cartografía del Chaco. Resistencia, Chaco.
\end{abstract}

Presentamos este trabajo en homenaje al

Agr. Nac, Lorenzo Lucio Bozikovic, que, como culminación de su larga trayectoria profesional en la actividad privada, fue nombrado Director de la Dirección Pcial. de Catastro y Cartografía de la Provincia del Chaco (1984 - 1991). Hombre con objetivos y metas claras, precursor e impulsor del Sistema de Información Territorial (S.I.T.), vio cumplido sus dos mayores anhelos en pos de un Catastro mejor, que fueron:

- $\quad$ poner en funcionamiento el S.I.T. (1996)

- la aprobación de la Ley de Catastro (2001)

\section{Resumen}

El trabajo consiste en un proyecto realizado en ArcView en el cual a modo de ejemplo se tomó el Dpto.Mayor Jorge Luis Fontana. Se presentan distintas capas temáticas tomando como base el Registro Gráfico Parcelario, cuya digitalización se realizó apoyándose sobre imágenes satelitales SPOT, el cual se relaciona con información alfanumérica contenida en la Base de Datos referida a los aspectos Físicos, Jurídicos y Económicos de la parcela.

\section{Objetivos:}

- DEMOSTRAR que las metas propuestas para el S.I.T. han sido logradas.

- DAR A CONOCER la información que se genera en la D.P.C y C. y que alimenta el S.I.T., el cual permite la explotación de la misma.

- DESTACAR la importancia de dicha información como base de apoyo cartográfico para otros sectores.

- $\quad$ RESALTAR el potencial del S.I.T.

\section{Palabras clave}

S.I.T.: Sistema de Información Territorial.

D.P.C. Y C. : Dirección Provincial de Catastro y Cartografia de la Provincia del Chaco.

VALUACION: conjunto de operaciones realizadas para hallar el justiprecio de las parcelas ubicadas dentro de la Provincia y no comprendidas en los ejidos municipales.

PARCELA: se llama a la cosa inmueble de extensión territorial continua, deslindada por un polígono de limites creados por un título jurídico, representada en un documento cartográfico de un Acto de Levantamiento Parcelario inscripto en el Organismo Catastral. (Ley № 4.901- Ley 4.851 Cap. II)

\section{Territorial Information System (T.I.S.) of Land Registry and Cartography of Chaco Province}

\section{Key words}

T.I.S.: Territorial Information System.

D.P.C. y C.: Land Registry and Cartography of Chaco Province

VALUATION: is the set of actions that is carried out to find the duly appraisal of the plots which are located inside the Province territory and excluded from municipal public land.

PLOT: it's the immovable matter of continuous territorial extension, demarcated by a polygon of limits created by a juridical title; and represented by a cartographic document coming from a Plot Surveillance Act, which is registered at the Land Registry. (Law $n^{\circ} 4.901$ - Law $n^{\circ} 4.851$, chapter II). 


\section{Introducción}

La misión del Catastro Territorial se sintetiza en una clásica definición: "... es la individualización y ordenamiento de la propiedad inmobiliaria por parte del Estado, en sus aspectos físico, jurídico y económico...". Cada uno de estos aspectos, en esencia, describen y registran los siguientes datos de la parcela:

\begin{tabular}{|c|c|}
\hline Físico & $\begin{array}{r}\text { ubicación, forma, dimensiones, superficies, planos y } \\
\text { hechos existentes; }\end{array}$ \\
\hline Jurídico & $\begin{array}{r}\text { títulos de propiedad, inscripciones, posesión y } \\
\text { demás derechos de los titulares; }\end{array}$ \\
\hline Económico & $\begin{array}{r}\text { mejoras existentes, infraestructuras, suelos, y } \\
\text { principalmente la valuación; }\end{array}$ \\
\hline
\end{tabular}

De acuerdo a lo expresado, la Dirección de Catastro y Cartografía de la Provincia del Chaco elabora y actualiza el catastro físico, jurídico y económico de la tierra rural, produciendo el padrón valuatorio para la facturación del impuesto inmobiliario, que calcula y percibe la Dirección General de Rentas.

Con respecto a los municipios, la misión de la D.P.C y C. es ejecutar y actualizar el catastro físico y jurídico, dado que el económico lo elaboran directa o indirectamente dichas instituciones. Es importante destacar que la D.P.C y C. codifica y asigna la nomenclatura, registra los planos de mensura y lleva el Registro Gráfico parcelario urbano, suburbano y rural de todo el territorio provincial.

EI PROYECTO S.I.T., fue financiado por el Banco Mundial con una contrapartida provincial, se implementó y puso en marcha en la D.P.C. y C. de la Provincia del Chaco entre los años 1996 y 1997.

El alcance del Proyecto fue definido para los inmuebles de la zona rural de la Provincia del Chaco.

El objetivo general de este proyecto fue:

- conocer el territorio, que se deriva de conocer cada parcela, en este caso de la tierra rural: uso del suelo, aptitud, infraestructura, valuación actualizada;

- detectar e incorporar las parcelas no registradas, a fin de producir un incremento en la facturación del impuesto inmobiliario.

Las metas, esencialmente, fueron:

- lograr la cartografía parcelaria actualizada, digitalizada y geo-referenciada de la Provincia, capturando información de imágenes satelitarias;

- lograr la interrelación de la información alfanumérica con la cartografía digitalizada; 
- obtener valuación parcelaria de la tierra rural con características diferenciales actualizadas.

Para cumplir estos objetivos y metas las principales actividades desarrolladas fueron: ampliación del edificio, contratación de consultores, capacitación del personal técnico y administrativo, llamados a licitación para: adquirir software, hardware, imágenes satelitales, realizar Trabajos de Campo ( densificación de los puntos trigonométricos con GPS y relación de estos puntos y los ya existentes del Instituto Geográfico Militar con hechos físicos identificables, determinación de puntos de apoyo terrestre para ejecutar la corrección geométrica de las imágenes P.A.I.S.)

Los Trabajos de Gabinete, sintéticamente, representan el procesamiento digital de las imágenes satelitarias con su corrección geométrica que constituyen la base cartográfica, la digitalización del Registro Gráfico ajustado a dicha base cartográfica, control de las áreas de las parcelas ya incorporadas para la detección de las parcelas aun no incorporadas, ingreso para la gestión del S.I.T. de la información vectorial y raster precedente y de la base alfanumérica existente.

La cartografía se apoyó en imágenes satelitales SPOT del año 1994-95, las cuales están comprendidas entre la orbita 693 al S.O. y 683 al N.O. haciendo un total de 51 escenas. Estas fueron georreferenciadas con Puntos de Apoyo de Imágenes Satelitales (P.A.I.S.) repartidos en su totalidad por el territorio provincial haciendo un total de 246, los mismos cuentan con monografías de ubicación real, para ser relacionados con la imágen en pantalla utilizando las herramientas que provee ERDAS 8.2 para el desarrollo del proceso. Proyección conforme: Gauss Krüger.

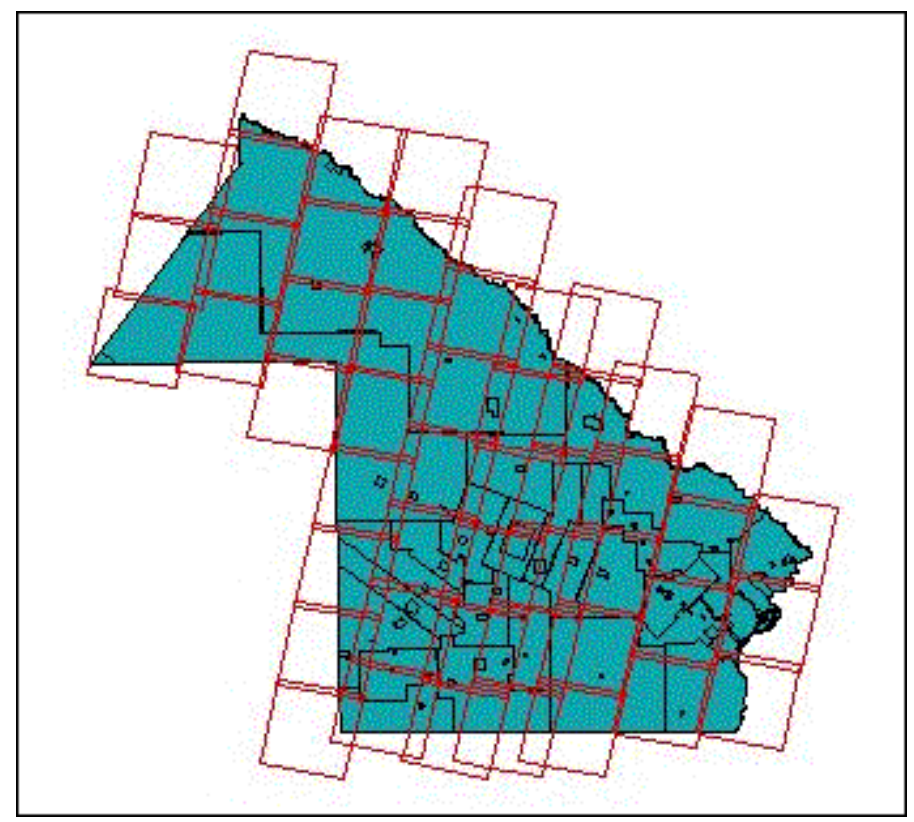

Figura 1. Distribución de imágenes satelitales.

Estos Trabajos de Gabinete fueron ejecutados por personal de la D.P.C. y C., el cual fue capacitado para asimilar el manejo de nueva tecnología, lo que asegura la continuidad del avance instituido por el Proyecto. 
Los productos de software adquiridos más importantes son: ARC/ INFO, para digitalización del Registro Gráfico; ArcView, para producción de informes gráficos en base a la información gráfica y alfanumérica disponible, Erdas Imagine para tratamiento de imágenes satelitales y Oracle Server, para manejo de la Base de Datos alfanuméricos.

A fin de completar el sistema implementado con el Proyecto S.I.T. se han desarrollado, en la Dirección, las aplicaciones para mantener actualizada la Base de Datos alfanumérica, para lo cual se compró el producto Oracle Developer 2000 y se contrató a un profesional especializado.

Los dispositivos de hardware más importantes adquiridos por medio de este Proyecto son: un sistema de computadoras conectadas en red, que consta de un servidor IBM Power PC RS/6000 C10 con sistema operativo AIX, estaciones de trabajo IBM Power RS/6000 y estaciones tipo PC, con sistema operativo Windows. Además se cuenta con un scanner de tamaño A0, de 800 dpi de resolución, un plotter HP DesignJet 750C, impresoras laser y mesas digitalizadoras.

\section{Desarrollo}

Para este trabajo se tomó como referencia al Dpto.Mayor Luis Jorge Fontana identificado a nivel provincial con el número 14, cuya cabecera es la localidad de Villa Ángela, seguida en importancia por Coronel Du Graty y Enrique Urien.

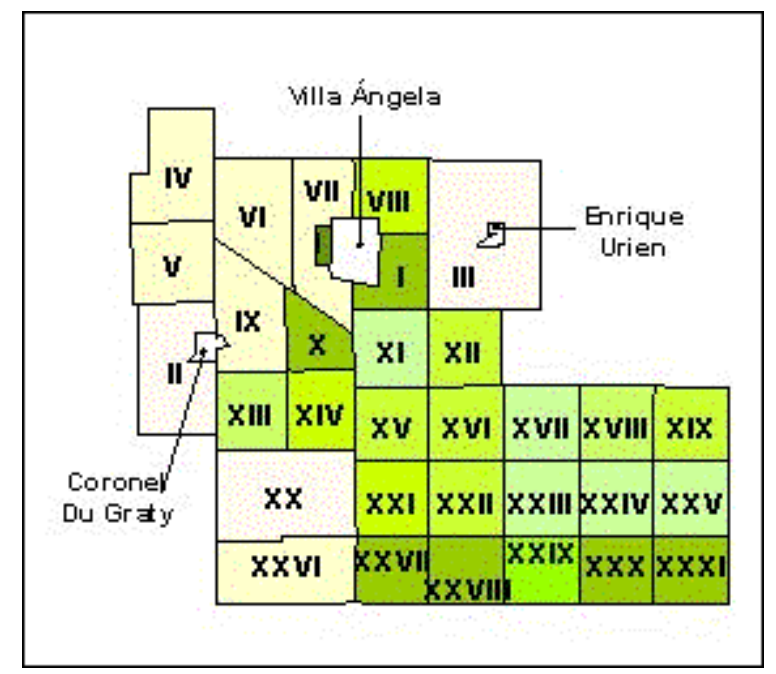

Figura 2. Departamento Mayor Luis Jorge Fontana

La superficie total es de $3.708 \mathrm{Km} 2$. Está Ubicado al S.O. chaqueño y tiene como límites:

O. : Dptos.12 De Octubre, 2 de Abril y Fray Justo Santa María de Oro

N. : Dptos.Chacabuco, O’Higginss y San Lorenzo

E. : Dptos.San Lorenzo y Tapenaga

S. : El paralelo 28 que determina el límite con la Provincia de Santa Fe. 
Las vías de comunicación terrestre más importantes que lo atraviesan son las Rutas Provinciales 95 (pavimentada) y 89 (tierra).

A fin de lograr los objetivos propuestos se elaboraron varias capas temáticas que ejemplifican la información disponible en la D.P.C. y C., referida a los tres aspectos de la propiedad inmobiliaria (físico, jurídico y económico).

El aspecto físico se refiere a la cartografía, que actualmente se encuentra digitalizada y georreferenciada, para ejemplificar se elaboraron dos capas temáticas:

Registro gráfico parcelario del departamento de referencia.

Uno de los elementos que componen el aspecto físico es la superficie. Considerando este elemento hemos realizado una comparación entre los departamentos Mayor Jorge Luis Fontana (14) y Tapenaga (23) donde se puede observar que en el primero hay una mayor subdivisión de la parcela con respecto al segundo. Para llegar a esta conclusión se seleccionó parcelas con superficie menor a 150 hectáreas.

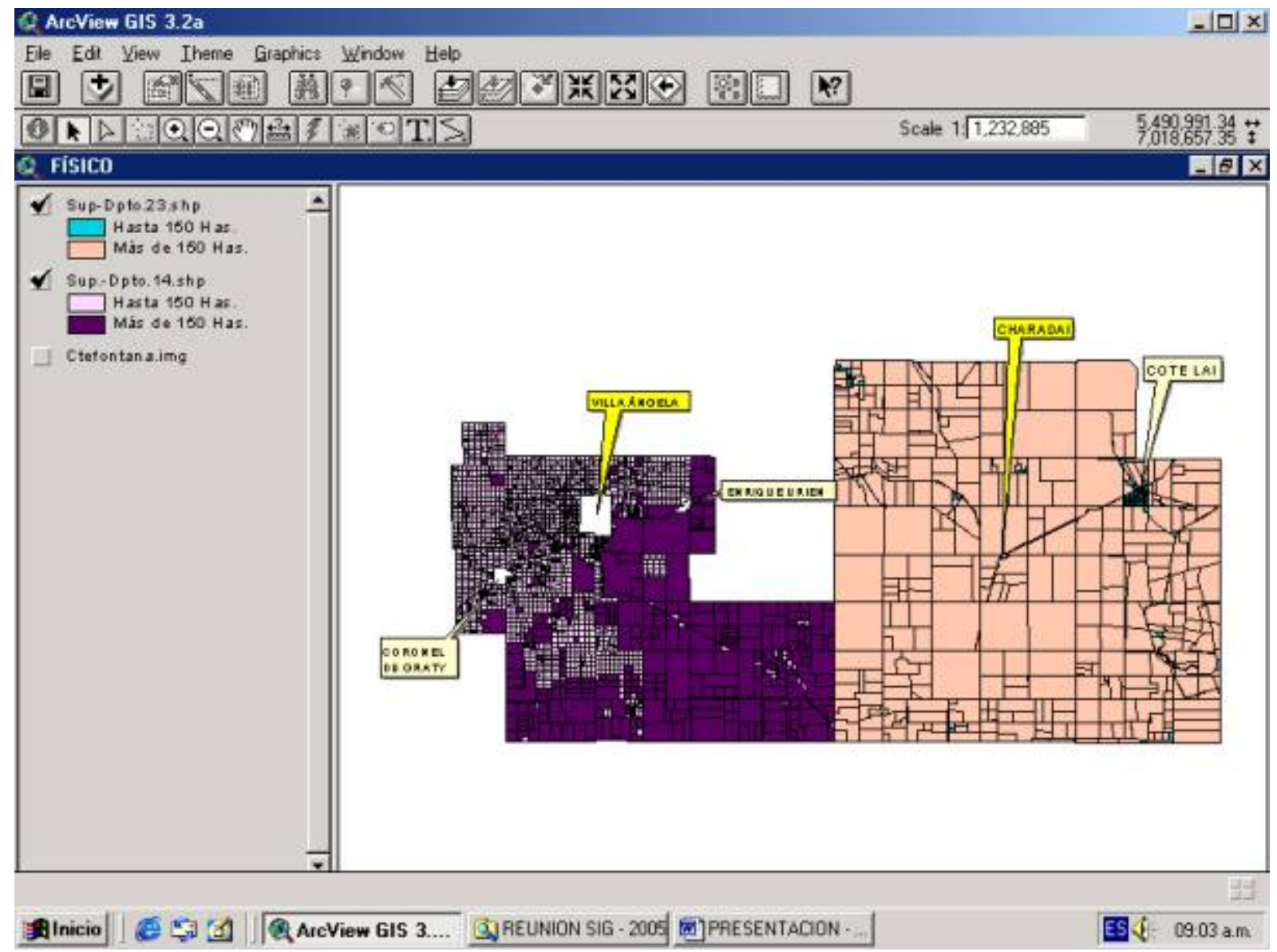

El aspecto jurídico se reflejó en dos capas temáticas:

Número especial con trabajos de la Primera Reunión de Usuarios De Sistemas de Información Geográfica - SIG - y Procesadores Digitales de Imágenes - PDI - del Nordeste argentino 
1. Se muestra el Estado Legal de la Tierra, clasificando los inmuebles de acuerdo al tipo de propietario (concesionario, fiscal o titular). Además se agregaron algunos datos de tablas, como ser: nombre del propietario, fecha de escritura y porcentaje de condominio.

2. Ubicación de inmuebles con destino específico, como ser: templos, escuelas, comisarías, Parque Provincial o Nacional, etc., los cuales en nuestra Base de Datos se identifican con un código particular.

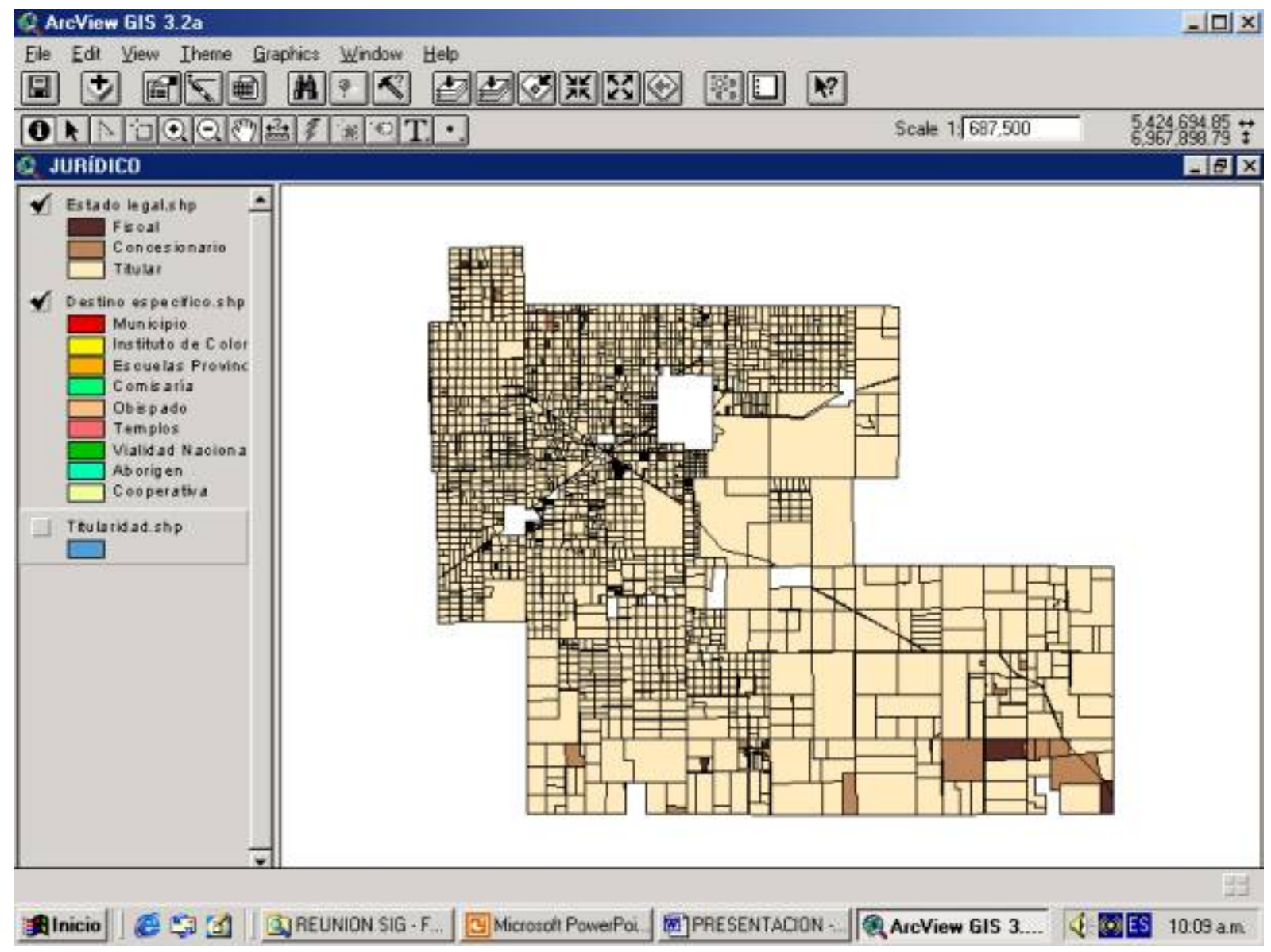

\section{El aspecto económico:}

La D.P.C. y C. calcula y emite la Valuación Fiscal libre de mejoras de las tierras rurales de la Provincia del Chaco. Cada Parcela rural tiene su característica propia para ello se utiliza una planilla con los factores diferenciales y específicos, como ser: ubicación e infraestructura, suelo, topografía, uso de suelo (agricultura, ganadería, bosque, laguna) y dos elementos mas que son electroducto (que deprecia el valor de la Parcela por estar sometida a restricciones) y electrificación rural (que valoriza la misma). Toda esta información esta cargada en la Base de Datos por lo que podemos seleccionar y graficar. A manera de ejemplo se tomaron los datos de los factores:

- Diferenciales y específicos de la parcela en cuanto a uso de suelo se graficó una capa temática para cada uso: 
Revista Geográfica Digital. IGUNNE. Facultad de Humanidades. UNNE. Año 2- No 4 Julio - Diciembre 2005. ISSN 1668-5180. Resistencia, Chaco

\section{- Agricultura \\ - Ganadería \\ - Bosque}

- Otra capa referida exclusivamente a Ganadería, considerando la característica de la flora, clasificando en:

- Tóxica

- No tóxica

$-$

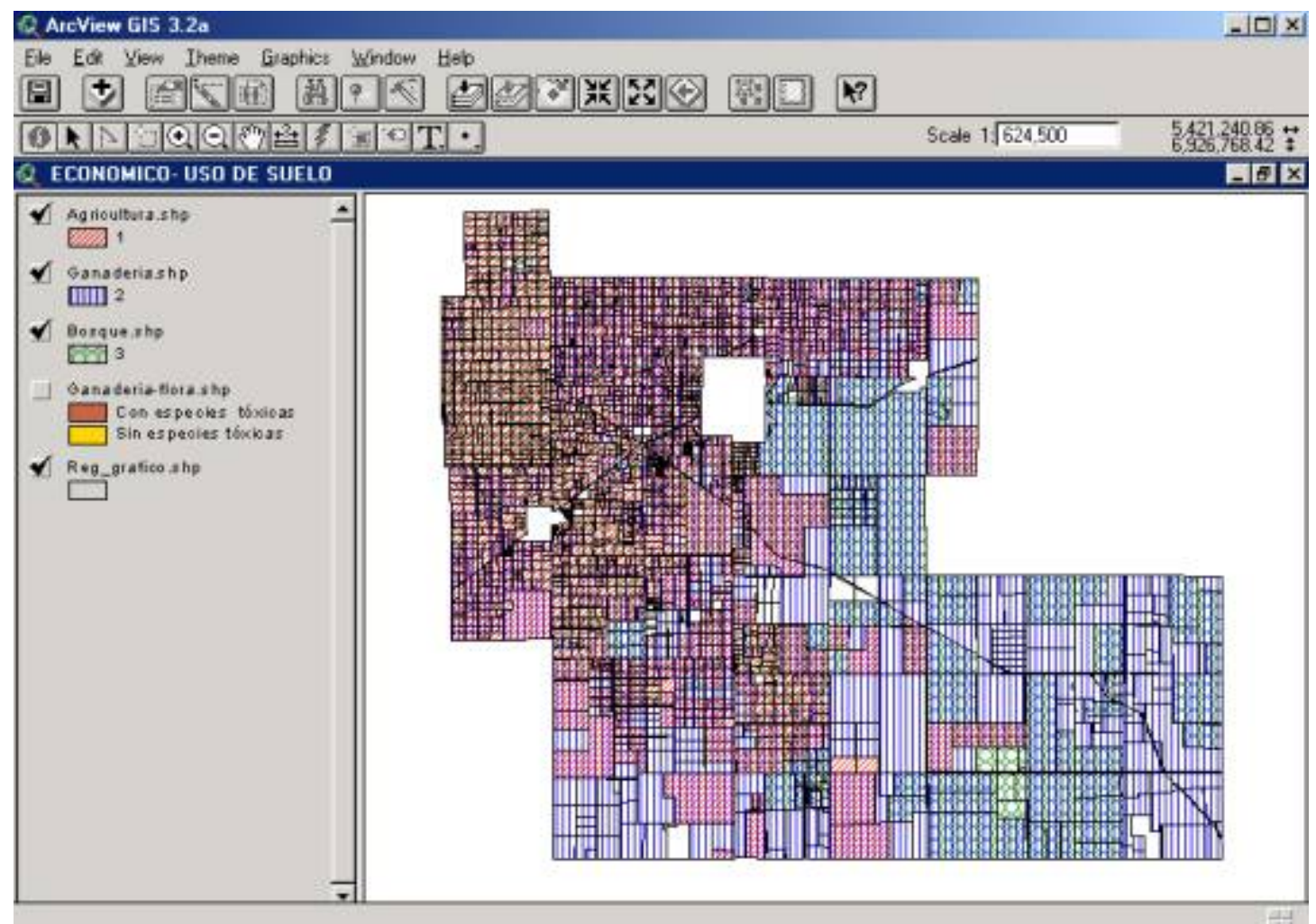

- Ubicación e infraestructuras:

Dentro de este factor se tomó "Distancias a rutas provinciales y nacionales", lo cual permitió graficar en función de cuatro aspectos
- $\square$ Sobre ruta
- $\square$ Hasta $1 \mathrm{Km}$.
- $\square \quad$ De $1 \mathrm{Km}$. а $3 \mathrm{Km}$.
- $\square$ De $3 \mathrm{Km} . \mathrm{A} 5 \mathrm{Km}$.
- $\square$ Más de $5 \mathrm{Km}$. 


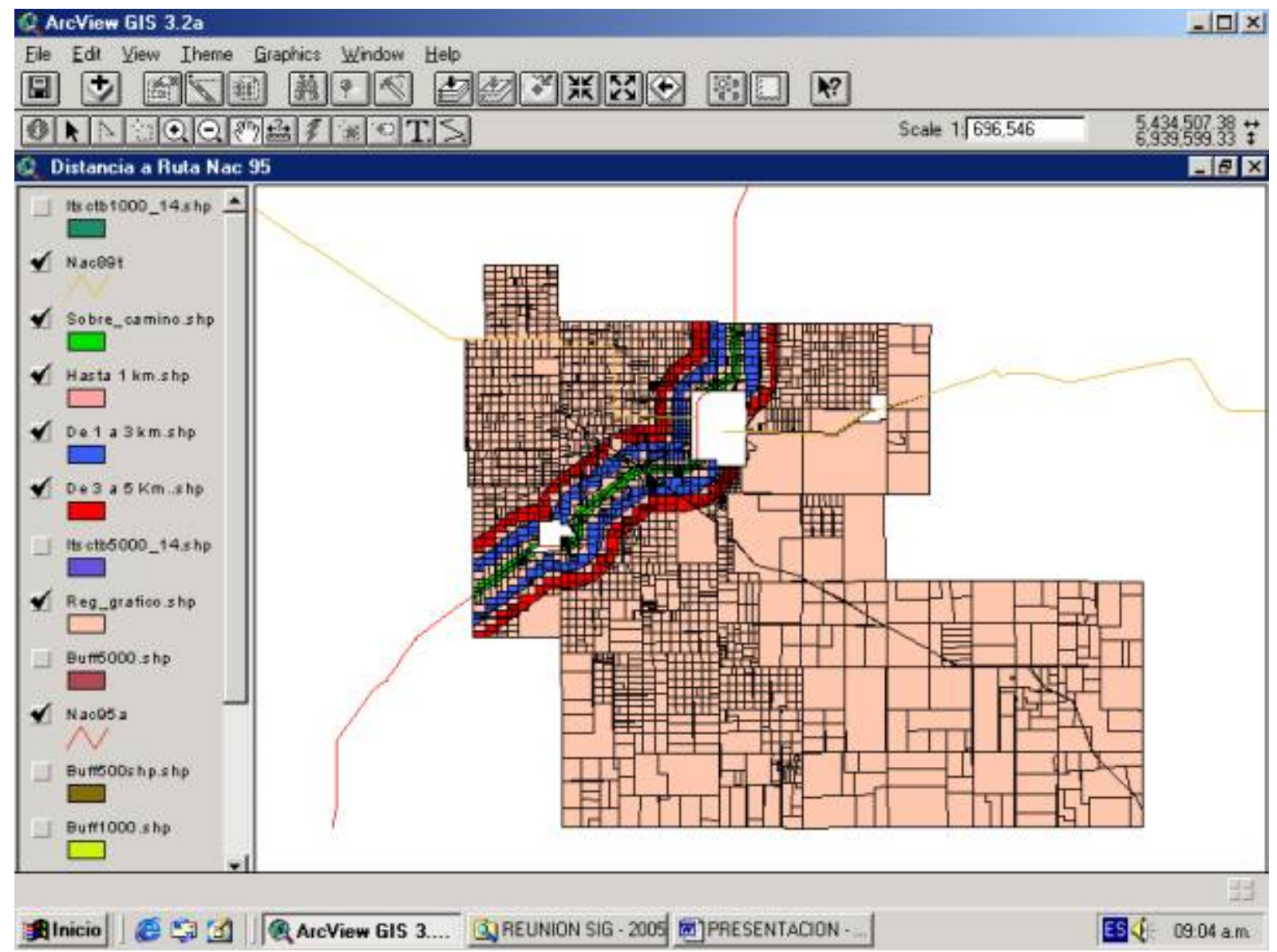

Número especial con trabajos de la Primera Reunión de Usuarios De Sistemas de Información Geográfica - SIG - y Procesadores Digitales de Imágenes - PDI - del Nordeste argentino 


\begin{tabular}{|c|c|c|c|c|c|c|c|c|c|c|c|c|c|c|c|c|}
\hline \multicolumn{9}{|c|}{ NOMENCLATURA CATASTRAL } & \multirow{2}{*}{$\begin{array}{c}\text { Tipo } \\
\text { Propied. }\end{array}$} & \multirow{2}{*}{ Partida } & \multirow{2}{*}{ Zona } & \multicolumn{5}{|c|}{ SUPERFICIE } \\
\hline & Departamento & Cire. & Secc. & $\mathrm{Ch}$. & Qta. & Frace. & Mz. & Pare. & & & & Hectireas & Areas & Cas. & Dms. & Cms. \\
\hline 14 & MAYOR LUIS J.FONTANA & 3 & & 33 & & & & & \begin{tabular}{|l|} 
Rural \\
\end{tabular} & 14264 & 15 & 105 & 0 & 0 & $\overline{0}$ & $\overline{0}$ \\
\hline
\end{tabular}
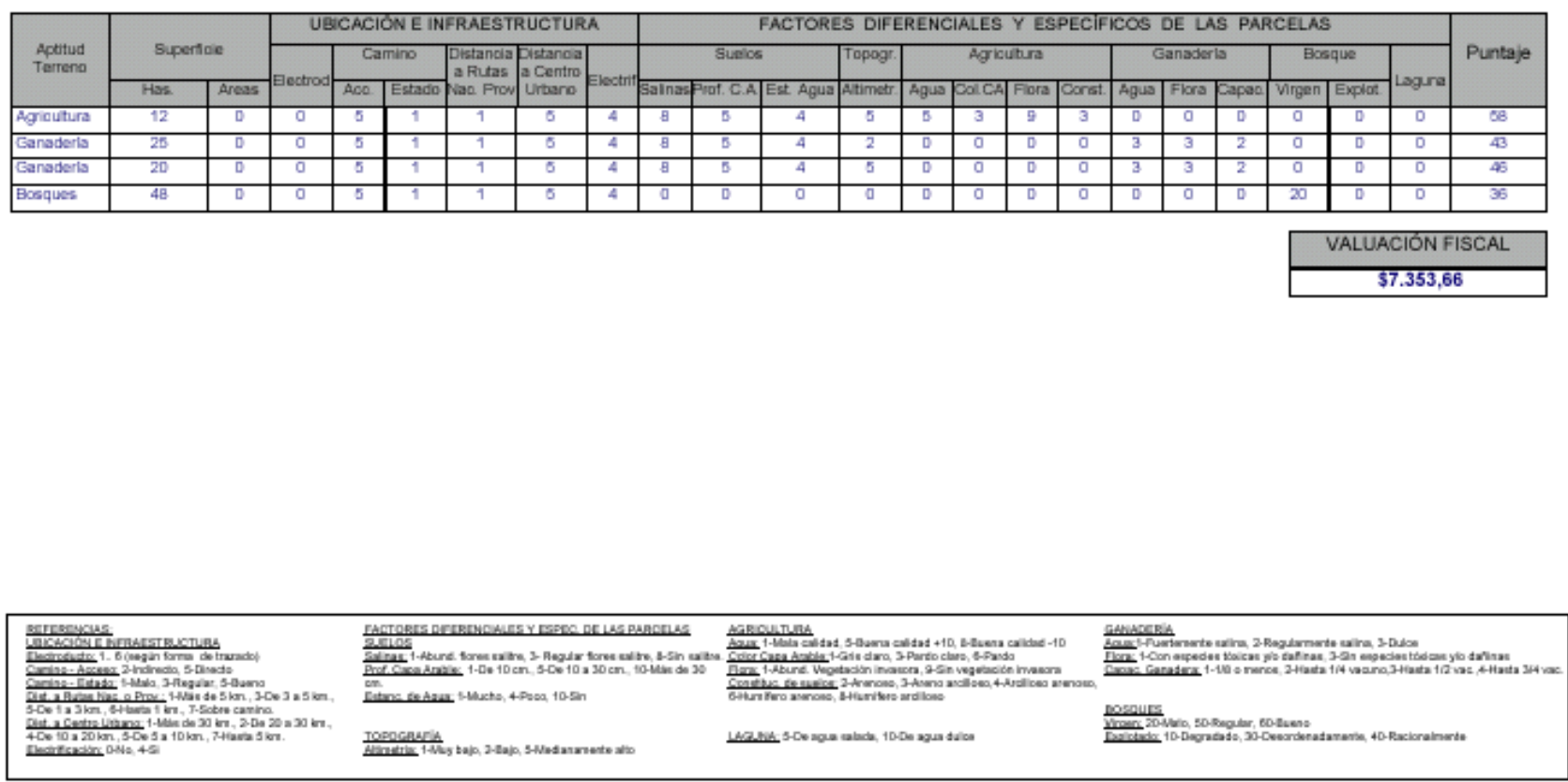

\section{CONCLUSION}

Para concluir transcribimos párrafos citados en el "Proyecto S. I. T." (Septiembre 1992 ) que reflejan el pensamiento del Agrimensor Lorenzo Lucio Bozikovic, ex Director de la Dirección Provincial de Catastro y Cartografía y Consultor de dicho Proyecto:

"El Director de Asuntos Jurídicos e Información Inmobiliaria del Servicio de Catastro y Registros Públicos de los Países Bajos Señor S. L. G. Henssen, en su obra "Nueva Legislación en el campo del Registro Inmobiliario y el Catastro en los Países Bajos" dice: "Desde la fundación del Servicio del Catastro y Registros Públicos este organismo se ha convertido en una institución que deriva su significación del hecho de haberse convertido en una fuente de información con respecto a los bienes raíces, para distintas finalidades; dicho de otro modo, se ha convertido, entre otras cosas en un sistema de datos inmobiliarios para distintos fines."

El aspecto del impuesto territorial ha pasado gradualmente a segundo plano.

Lo que quiere significar al describir el Catastro como “...fuente de información...para distintas finalidades..." es que, tal como sucedió en años anteriores, ya no sirve solamente para la finalidad de la seguridad jurídica o aplicación de impuestos, sino también para otros fines, tales como la consolidación territorial, la planificación física, la administración territorial, el urbanismo y la estadística. Este sistema de información es plurivalente o podemos hablar de un Catastro plurivalente en el sentido más amplio. Esta 
metamorfosis o evolución fue uno de los motivos de crear una nueva legislación para los Registros Públicos y el Catastro (código civil y ley catastral).

Dentro de este marco es razonable aprovechar la estructura de nuestro Catastro para ingresar datos a la base obtenidos por otros equipos de trabajo que se apoyan en nuestro sistema parcelario, cuya actualización demanda tiempo y costo, lo que no hace aconsejable su desdoblamiento el que envejecería rápidamente.

Para finalizar, queremos recordar las palabras con que el Agrimensor Víctor Haar concluyó su conferencia en La Plata: "Aunque si bien en nuestro país se habla constantemente de la importancia de la informática y de que tenemos que superar el atraso tecnológico, se está descuidando el principal de todos los sistemas de información que es el Sistema de Información Territorial, porque es el que les da todos los elementos a los gobernantes para poder tomar decisiones correctas". 